\title{
Using pedigree information to monitor genetic variability of endangered populations: the Xalda sheep breed of Asturias as an example
}

\author{
By F. Goyache ${ }^{1}$, J. P. Gutiérrez ${ }^{2}$, I. Fernández ${ }^{1}$, E. Gomez ${ }^{1}$, I. Alvarez ${ }^{1}$, J. Díez ${ }^{1,3}$, \\ and L. J. Royo
}

\begin{abstract}
Summary
The aim of this work is to highlight the need of monitoring small populations to conserve their genetic variability by using a set of parameters to characterize both the structure of populations and management practices. As a representative example we analyse the pedigree information of the endangered Xalda sheep breed of Asturias. The herdbook of Xalda sheep included a total of 805 animals and 62 herds. The number of founders was 329. Nowadays, there are 562 live animals and 26 active herds. The breed is in risk of losing genetic diversity because of the abusive use of certain individuals as parents. The effective number of founder animals is 81.1. The effective number of founder herds is 9.9. The average value of inbreeding in the whole Xalda population was $1.5 \%$. The average relatedness (AR) coefficient reached $1.8 \%$ in the whole pedigree. The genetic representation of the lines of founders is unbalanced. Inbreeding trends and effective size do not provide realistic information concerning the risk of loss of diversity as a result of the shallowness of the genealogical information. We suggest the monitoring of the breed using AR to unbalance the genetic contributions of specific individuals, equalizing the genetic representation of the founders and lines in the population. In addition, AR can suggest the introduction of new, under-represented animals in herds showing high average AR values relative to the population. Our results can be useful to improve the development of conservation initiatives involving open herdbooks to avoid the risk of loss of genetic diversity caused by incorrect management practices.
\end{abstract}

\section{Zusammenfassung}

Verwendung von Pedigree Informationen zur Konservierung genetischer Variabilität in gefährdeten Populationen: Das asturische Xalda Schaf als Beispiel

Das Ziel dieser Arbeit ist es, die Notwendigkeit hervorzuheben, Pedigree Informationen in kleinen Populationen durch Verwendung bestimmter Parameter zu analysieren, um sowohl die Struktur der Populationen als auch Managementmaßnahmen zu charakterisieren. Als repräsentatives Beispiel analysieren wir Pedigree Informationen des gefährdeten Xalda Schafes in Asturien. Das Herdbuch des Xalda Schafes umfasst 805 Tiere in 62 Herden. Die Population ging aus 329 Tieren hervor. Zur Zeit beträgt die Population 562 lebende Tiere und 26 aktive Herden. Die Rasse ist aufgrund der starken Nutzung weniger Individuen als Elterntiere in Gefahr, genetische Variabilität zu verlieren. Die effektive Zahl an Gründertieren ist 81,1, die an Herden 9,9. Der durchschnittliche Inzuchtkoeffizient in der gesamten Xalda Population war 1,5\%. Der durchschnittliche Verwandtschaftskoeffizient (AR) erreichte $1,8 \%$ im gesamten Pedigree. Die genetische Repräsentation der Ausgangslinien ist nicht ausgewogen. Der Inzuchtzuwachs und die effektive Größe bringen aufgrund unzureichender genealogischer Daten keine realistischen Informationen bezüglich Gefährdungsstatus. Wir empfehlen eine Untersuchung der Rasse unter Verwendung von AR, um die genetischen Anteile spezifischer Individuen auszugleichen und um die unausgewogene genetische Repräsentation der Gründer und Basislinien in der Population auszugleichen. Die Verwendung von AR legt die Nutzung neuer, unterrepräsentierter Tiere in den Herden nahe, die hohe durchschnittliche AR Werte im Vergleich 
zur Gesamtpopulation aufweisen. Unsere Ergebnisse können für die Weiterentwicklungen von Konservierungsmaßnahmen wie offene Herdbücher nützlich sein, um das Risiko eines Verlustes genetischer Diversität durch fehlerhafte Zuchtmaßnahmen zu vermeiden.

\section{Introduction}

The protection of the genetic base of a population in risk has usually been measured by the rate of inbreeding. This parameter measures the rate of loss of genetic variability and gives an indication of the potential build-up of unrecognized lethal recessives. However, the computation of the individual coefficient of inbreeding is highly sensitive to the quality of the available pedigree information and is affected by the fact that actual populations of domestic animals do not remain closed for considerable periods of time. These topics make the estimations of inbreeding difficult to interpret, as incomplete pedigrees lead to an underestimation of inbreeding and the introduction of animals in a population immediately reduces inbreeding (BOICHARD et al. 1997).

Consequently, a number of techniques have been proposed to monitor the amount of genetic diversity in a population. LACY $(1989,1995)$ introduced two relevant new concepts: (a) the 'effective number of founders', which measures the overall founder representation in a population accounting for the loss of genetic variability from unequal founder contributions, and (b) the 'founder genome equivalents', which characterizes the genetic diversity in the actual population if the founders were equally represented, accounting for all reasons for loss of genetic diversity. BoICHARD et al. (1997) proposed the 'effective number of ancestors' to account for bottlenecks in the population, which is the major cause of gene loss in captive populations. AldDERSON (1991) proposed equalizing founder contributions by selecting for breeding the individuals with the highest effective number of founders. However, if the pedigree information for a given animal is unbalanced, animals in the earliest generations would be rejected as future parents because the effective number of founders in their pedigree would be small. Thus, we may prefer to unbalance the offspring of the parents towards those with a lower level of genetic representation in the population in an attempt to maintain the initial genetic variability (BALlOU and LACY 1995). To overcome these problems, some recent works used the average of the coefficients in the row in the numerator relationship matrix for each individual (called 'average relatedness') to ensure the minimum increase in inbreeding regardless of overlapping and concentration of influences by lines and generations (DuNNER et al. 1998; GuTIÉRREZ et al. 2003). As genetic variability depends largely on the size of the base population, the use of the average relatedness coefficient would be indicated to increase the representation of the founders in the present population.

In addition, to establish appropriate management of the genetic stock of a population, we should not only evaluate it in terms of inbreeding and probabilities of gene origin to know the evolution of its gene pool, but also study its structure and demography as a complementary subject. Hall $(1986 ; 1989)$ pointed out that the gene flow among farms is the statistics of most value for monitoring breeds. Demographic analysis allows us to describe the structure and dynamics of populations considered as a group of renewed individuals, highlighting important circumstances affecting the history of the genes of the population.

The Xalda (Alvarez Sevilla et al. 1982) is a sheep breed mainly located in Asturias (Northern Spain). Alvarez Sevilla (2001) considers that Xalda sheep may be included within the Celtic sheep breeds like the French Ouessant and the British Black Welsh and Morite. The Iberian sheep breeds that may be close to Xalda are extinct (Churra Berciana in Spain) or under a high risk of extinction (Bordaleira in Portugal). Alvarez Sevilla et al. (1982) estimated that in 1980 hardly 800 pure reproductive females remained. During the 1990 s, breeders made a major effort to recover isolated herds and individuals by starting pure breed matings. 
The aim of this work is to highlight that no single tool is useful by itself to characterize the status of risk of a population. To asses the level of endangerment and conserve the genetic variability of small populations it is necessary to monitor them by using a set of parameters characterizing both the structure of populations (at individual and herd levels) and management practices. To exemplify it we analyse the information from the Xalda sheep herdbook as a representative example of the initiatives in conservation of animal genetic resources developed in Europe.

\section{Material and methods}

We analysed the pedigree information registered by the Xalda sheep Breeders Association (ACOXA) from the foundation of the Xalda herdbook in 1992 to December 2001. According to geographical origin and the importance in the retrieval of the breed, ACOXA distinguishes between nine lines: Adrao, Antón, Arquil.lina, Brañaseca, Candanéu, Eilao, Eirrondo, Ixuxu and Oubal.lu. Most used rams and their mothers come from these lines. Founder animals included in these lines were recovered before or in the early days of the foundation of the Xalda herdbook. Founder animals included in the herdbook were usually recovered in groups in the same herd or in different herds in the same location. Herds of origin were registered in the herdbook. A total of 805 animals are registered in the herdbook. Up to 31 December 2001, 562 animals (507 females) remained alive. There are 329 registered animals with unknown parents (58 males and 271 females) and 80 additional registered individuals with only one known parent as founder animals. The Xalda population is mainly young, $39 \%$ of the living individuals being younger than 2 years and $45 \%$ aged between 3 and 5 years. The total number of herds historically registered in the herdbook is 62 . However the number of active herds each year is substantially lower (26 in 2001).

Information on the contribution of the registered rams and herds to the Xalda herdbook is presented in Fig. 1. Most of the 50 rams historically used produced six offspring or fewer to be included in the herdbook, while nine produced more than 20 offspring. Only five rams produced 30 or more offspring, totalling $31 \%$ of animals included in the herdbook with a known father. Sixty per cent of the total registered herds contributed with 10 offspring or fewer to the herdbook, while $10 \%$ originated between 20 and 40 registrations and five herds originated between 41 and 75 registrations. These last five herds originated $34 \%$ of the animals included in the herdbook.

To characterize the structure of the Xalda population, we analysed the following parameters:

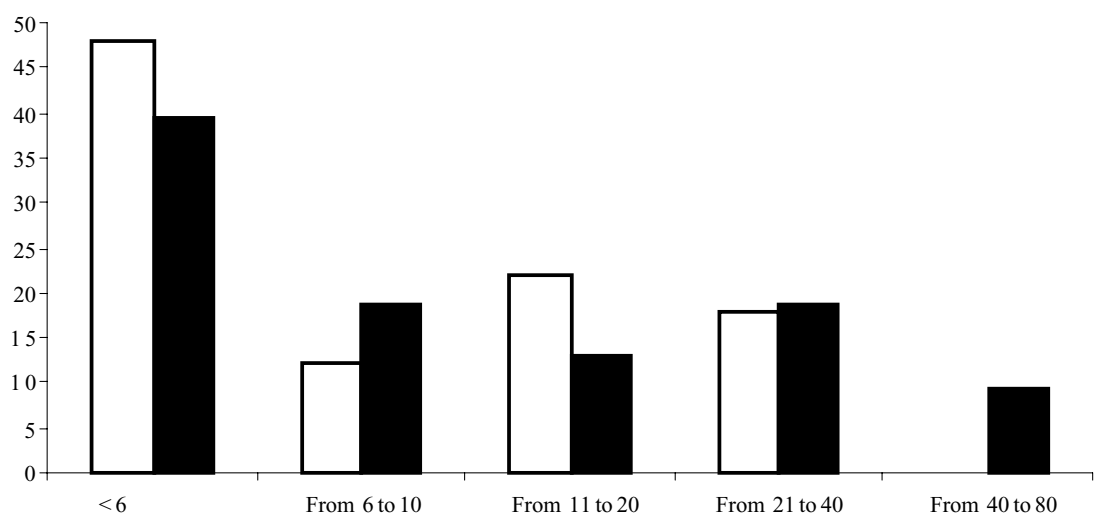

Fig.1. Relative (in percentage) frequencies of rams (white bars) and herds (black bars) by number of offspring registered in the xalda's herdbook 
(1) Herds contributing with rams to the population. We followed the criteria proposed by VASSALLO et al. (1986) classifying the herds as: (a) nucleus herds, if breeders use only their own rams, never purchase rams but sell them; (b) multiplier herds, when breeders use purchased rams and also sell rams; and (c) commercial herds that never sell rams. The methodology we use here is suitable for analysing populations of an unknown structure and permits us to analyse the data without predefining a nucleus in our population.

(2) Genetically important herds. This parameter was analysed by the three methods proposed by BARKER (1957): (1) appearances of the males from a herd as fathers; (2) appearances of each herd in the father-of-ram line; and (3) total appearances of the reproductive males from a herd in all the possible pathways. An appearance in the parental generation was scored as 4, an appearance in the grandparental generation was scored as 2, and an appearance in the great-grandparental generation was scored as 1 .

(3) Generation lengths. This is the average age of parents at the birth of their useful offspring. We computed this for the four pathways (ram-son, ram-daughter, ewe-son and ewe-daughter) using birth dates of registered animals together with those of their rams and ewes.

(4) Number of known generations and number of equivalent generations (GuTIÉRREZ et al. 2003). The former was computed as the generations separating the offspring from its furthest known ancestor and the later as the sum of $(1 / 2)^{\mathrm{n}}$ where $\mathrm{n}$ is the number of generations separating the individual to each known ancestor. Ancestors with no known parent were considered as founders (generation 0 ).

(5) Effective number of herds supplying fathers $\left(H_{\mathrm{S}}\right)$, grandfathers $\left(H_{\mathrm{SS}}\right)$ and greatgrandfathers ( $\left.H_{\mathrm{SSS}}\right)$ (ROBERTSON 1953). These parameters are computed as the inverse of the probability that two animals taken at random in the population have their parent in the same herd for each path.

(6) Effective number of founder herds $\left(f_{\mathrm{h}}\right)$. This is computed as the inverse of the summed squared of the sum of the contributions of founders into each herd.

Both concentration of the gene origin and inbreeding levels were estimated by computing the following parameters:

(1) Effective number of founders $\left(f_{\mathrm{e}}\right)$ (LACY 1989). This is defined as the number of equally contributing founders that would be expected to produce the same genetic diversity as in the population under study. This is computed as: $f_{\mathrm{e}}=1 / \sum_{\mathrm{k}=1}^{\mathrm{f}} \mathrm{q}_{\mathrm{k}}^{2}$, where $\mathrm{q}_{\mathrm{k}}$ is the probability of gene origin of the $\mathrm{k}$ ancestor.

(2) Effective number of ancestors $\left(f_{\mathrm{a}}\right)$. This is the minimum number of ancestors, not necessarily founders, explaining the complete genetic diversity of a population (BOICHARD et al. 1997). Parameter $f_{\mathrm{a}}$ does not fully account for gene loss by drift from the ancestors to a reference population, but complements the information offered by the effective number of founders accounting for the losses of genetic variability produced by the unbalanced use of reproductive individuals producing bottlenecks. To compute $f_{\text {a }}$, one must consider only the marginal contribution of an ancestor, which is the contribution made by an ancestor that is not explained by other ancestors chosen before.

(3) Individual inbreeding coefficient (F) (WRIGHT 1931). This is defined as the probability that an individual has two identical alleles by descent. We computed this for the whole known pedigree and for each of the known generations by means of a modification of the algorithm proposed by Meuwissen and LuO (1992).

(4) Effective population size $\left(N_{\mathrm{e}}\right)$ (WRIGHT 1931). This is defined as the number of individuals that would give rise to the calculated rate of inbreeding if they bred in the manner of the idealized population. $N_{\mathrm{e}}$ was computed as

$$
N_{\mathrm{e}}=\frac{1}{2 \Delta F}
$$


(5) The average relatedness coefficient (AR) of each individual (DUNNER et al. 1998; GutiÉRrez et al. 2003). This is the average of the coefficients in the row correspondent to the individual in the numerator relationship matrix (A). In founder individuals AR can be computed by assigning to each individual, a value of 1 for belonging to the population, $1 / 2$ for each son the animal has in this population, $1 / 4$ for each grandson and so on, and weighting according to the size of the population. In consequence, AR indicates the genetic contribution of founders to the population and can be used as an index to maintain the initial genetic stock as well as to compare inbreeding among subpopulations.

The reference population used to compute the parameters above is the whole known pedigree (given its small size) including founders. However, to compute parameter $f_{\mathrm{a}}$ we used as reference population the non-founder animals born in 1996 or later to assess the genetic variability existing in the present population.

\section{Results and discussion}

The concentration of the origin of the animals in a population can be characterized by analysing the structure of the herds. Table 1 shows the classification of the Xalda herds according to the origin and use of their rams. We cannot find herds acting as a nucleus in the way proposed by Vassallo et al. (1986). No registered herd uses only their own rams and sells rams to the others. Half of the herds can be classified as multipliers, as their owners purchase, sell and use their own rams $(28.6 \%)$ or purchase and sell rams. The others are commercial herds that do not sell rams. However, the percentage use of purchased rams is always high (from 75 to $80 \%$ ), regardless of whether the herds are considered as multiplier or commercial. Additionally, we applied the methodology proposed by BARKER (1957) to identify relevant herds in the Xalda herdbook. There are 12 herds $(19 \%$ of the total registered herds) producing rams that appear as reproductive males at least $5 \%$ in all the distinct paths of the pedigree. However, only eight of these herds would be considered relevant if we take into account only the appearances of reproductive males as rams or grand-rams. Just five herds would be considered relevant at the same time for rams or for grand-rams.

The actual and the effective number of herds supplying rams is 16 (Table 2), characterizing the high number of herds where the recovery of founders was performed. The effective number of herds supplying grand-rams and great-grand rams are eight and three, respectively. Despite a large number of herds being considered founders, the effective number of founder herds is 9.9. In breeding terms, there is a high concentration of the origin of the reproductive animals.

All these results characterize our breed as a frail population based on a small number of farms and farm-parks, which constitute the hard core of the breed. The herdbook includes the herds of origin of founders and a high proportion of hobby farmers, who usually remain members of ACOXA for a short time. These herds remain in the herdbook

Table 1. Herds registered in the herdbook of Xalda sheep breed classified according to the origin and use of the herd's rams

\begin{tabular}{|lccccc|}
\hline Classification & $\begin{array}{c}\text { Using purchased } \\
\text { rams }\end{array}$ & $\begin{array}{c}\text { Using own } \\
\text { rams }\end{array}$ & $\begin{array}{c}\text { Selling } \\
\text { rams }\end{array}$ & $\begin{array}{c}\text { Percentage } \\
\text { of herds }\end{array}$ & $\begin{array}{c}\text { Percentage of } \\
\text { purchased rams }\end{array}$ \\
\hline Nucleus herds & No & Yes & Yes & 0 & 0 \\
Multiplier herds & Yes & Yes & Yes & 29 & 75 \\
& Yes & No & Yes & 21 & 100 \\
Commercial herds & Yes & Yes & No & 3 & 80 \\
& Yes & No & No & 47 & 100 \\
Disconnected herds & No & Yes & No & 0 & 0 \\
\hline
\end{tabular}


Table 2. Parameters characterizing the concentration of origin of the animals in the Xalda sheep breed: effective number of herds contributing reproductive males $\left(H_{\mathrm{S}}, H_{\mathrm{SS}}\right.$ and $\left.H_{\mathrm{SSS}}\right)$, and actual and effective number of founder herds

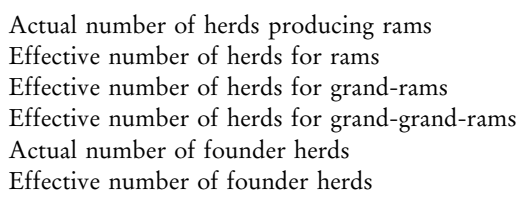

regardless of whether their animals were spread over other herds a little later. However, despite the core herds of ACOXA remaining practically the same throughout the 1990's, the influence of some of these decreases substantially if we take into account the appearances of their reproductive males as grand-rams or rams. This suggests a drop in the involvement of the pioneers in the recovery of the breed. In this sense, the breed presents a substantial structural risk (GAMA and DELGADo 2000). The breed has, of course, a small number of reproductive females and uses a very reduced number of rams, but furthermore, its conservation is dependent on the standing of a small number of herds and is very sensitive to the withdrawal of some of these core herds. This is specially true when we considered the unbalanced contribution of the herds to the gene pool. A small number of herds supply the fathers of the rams to the rest of the population. Moreover, despite the existence of founder animals in a large number of herds, the genetic variability of the breed can be considered as being provided by the contribution of just $18 \%$ of the total number of registered herds.

The average generation length is roughly 3 years (Table 3 ). The pathway on the ram is always shorter than the pathway on the ewe. The shortest generation length corresponds to the pathway ram-son (2.7 years) while the longer is the pathway ewe-daughter (3.11). Generation length in our breed is relatively short in comparison with others reported in the literature. Prod'homme and Lauvergne (1993) found that the generation interval in a closed Merino Rambouillet flock, during about 50 generations of inbreeding, was between 2.2 and 4.1 years on the ram side, and between 3.9 and 5.6 years on the side of the ewe. DJellati et al. (1994) found average generation lengths in Solognote and Mérino Précoce breeds of between 2.5 and 3.5 years on the ram pathway and of 4.5 years for that of the ewe. All these French breeds underwent a program to conserve their genetic variability that included shortening the interval on the ram-offspring way. The generation intervals on the ram in Xalda sheep are comparable with those found in the French breeds, while the pathways on the dam are shorter. In Xalda sheep, breeders conserve all the females they obtain. The pathway ram-son is the shortest, because breeders select a son of the only reproductive male they usually have as a future ram. However, breeders decide about the mother of a ram when they have sufficient information on the ewe's performance (at least two lambs). This may explain why the generation length on the pathway ewe-son is the longest.

Table 3. Generation intervals (in years) for the four pathways father-son in the pedigree of the Xalda sheep breed

\begin{tabular}{|lrc|}
\hline Pathway & $N$ & Years \\
\hline Ram-son & 98 & 2.67 \\
Ram-daughter & 434 & 2.86 \\
Ewe-son & 91 & 3.23 \\
Ewe-daughter & 329 & 3.11 \\
Average & & 2.97 \\
\hline
\end{tabular}


Table 4. Parameters characterizing the concentration of gene origin in the Xalda sheep breed: actual and effective number of founder animals and effective number of ancestors

$\begin{array}{lc}\text { Equivalent number of founder animals } & 369 \\ \text { Actual number of founder animals } & 329 \\ \text { Effective number of founder animals } & 81.1 \\ \text { Effective number of ancestors } & 40.2 \\ \text { Number of ancestors explaining } 50 \% & 13 \\ \text { Number of ancestors explaining } 70 \% & 36\end{array}$

Table 4 shows the parameters characterizing the concentration of gene origin in the whole known pedigree. The equivalent number of founders is 369 , which sum up $46 \%$ of the total registered animals. However, the effective number of founders is substantially lower (81.1). This indicates the excessive use of some individuals as parents. The effective number of ancestors $\left(f_{\mathrm{a}}\right)$, computed following BoICHARD et al. (1997), is 40.2. The total number of ancestors selected by computing $f_{\mathrm{a}}$ is 236 , which is $29 \%$ of the total animals in the population and $72 \%$ of the founders. This relatively high number of ancestors is typical of populations lacking long historical pedigrees showing a short time period between the youngest generations and the founders (GUTIÉRREZ et al. 2003). The number of ancestors explaining $50 \%$ of the genetic variability in the Xalda breed is 13 and just 36 explain $70 \%$. The effective number of ancestors is useful to detect recent significant changes in the breeding strategy. A favourable morphological selection has probably increased the representation of some individuals in the whole pedigree. This practice, which might not be evident for breeders, represents a serious risk for the conservation of the genetic background in Xalda population.

The average values of $F, \mathrm{AR}$, number of known generations and number of equivalent generations are described in Table 5. The mean $F$ in the whole pedigree is $1.5 \%$ and the average AR is $1.8 \%$. These values are higher for males than for females and for live animals than for dead ones. Inbred animals are $11 \%$ of the population. Their mean $F$ is considerably high $(14.41 \%)$, and their mean AR is twice that found for the whole pedigree. Inbreeding accumulated in the last 3 years (Fig. 2). $F$ is 0 from the foundation of the herdbook to 1993. In this said year, the number of animals without known parents registered in the herdbook dropped considerably, leading to $F$ reaching $2 \%$ in 1994 . The registration of a high number of founder animals till 1998 maintained $F$ at levels below 1\%. In the last 3 years of our study, very few founders were included in the herdbook and the underlying inbreeding existing in the breed appears. AR reached 1-2\% 2 years before the genetic relationships existing between individuals could be measured as inbreeding. AR was higher than $1 \%$ between 1995 and 1998, bringing forward a possible rise in the overall inbreeding. AR acts as a good indicator of the long-term inbreeding of a population. When AR reaches high relative values, matings should be carefully planned, otherwise it will be easy to find crosses between individuals showing a certain degree of relatedness. Of course, the present analysis takes into account the whole genealogical information. Computed AR values are

Table 5. Average values of inbreeding $(F)$, average relatedness (AR), number of known generations and number of equivalent generations for the Xalda pedigree completeness level and for the inbred animals $F$ and AR values are expressed in percentages

\begin{tabular}{|lcccccr|}
\hline & Whole pedigree & Inbred & Males & Females & Alive & Dead \\
\hline$N$ & 805 & 86 & 124 & 681 & 561 & 244 \\
$F(\%)$ & 1.54 & 14.41 & 2.01 & 1.45 & 1.76 & 1.03 \\
AR $(\%)$ & 1.79 & 3.63 & 2.60 & 1.64 & 1.90 & 1.52 \\
Known generations & 1.80 & 3.67 & 2.28 & 1.70 & 1.94 & 1.44 \\
Equivalent generations & 1.09 & 2.50 & 1.45 & 1.02 & 1.18 & 0.87 \\
\hline
\end{tabular}




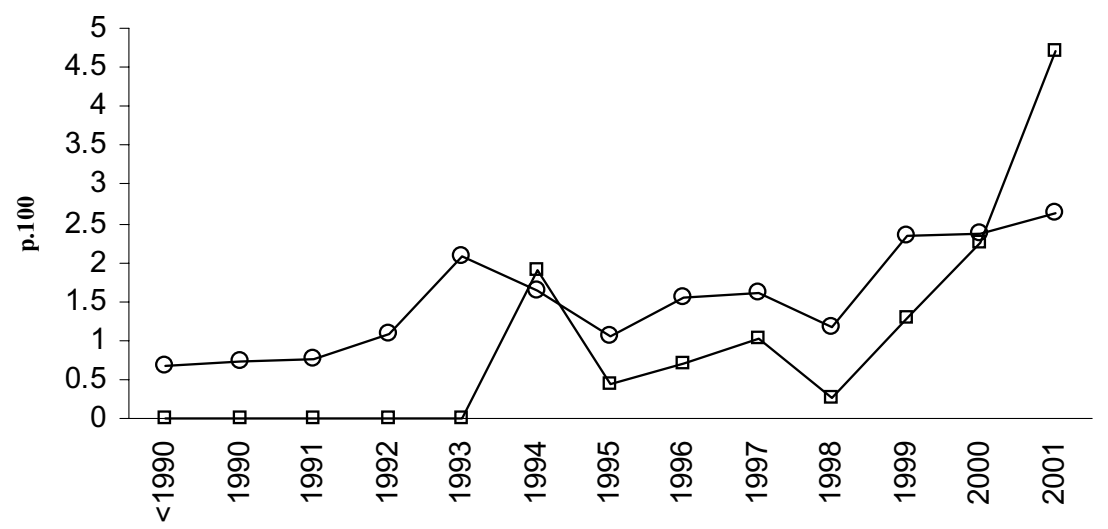

Fig. 2. Increase of inbreeding $(\square)$ and average relatedness $(\bigcirc)$ - in percentage - in the Xalda breed by year of birth

influenced by the reproductive use of individuals. To check how breeding management increased the genetic similarity of the animals of our population we computed $F$ and AR for the animals born till 1999. After this year the inclusion in our herdbook of individuals with unknown parents was irrelevant. Up to 1999 the average $F$ and AR values for the whole pedigree were, respectively, of 0.66 and $1.37 \%$. The gradual registration of a high number of founders in the herdbook kept inbreeding in relatively low levels. However, the mean AR value of the population shows that individuals were highly genetically related. In the last 3 years breeders had difficulties to carry out matings between unrelated animals. The higher average AR values of our males suggest that $F$ will increase quickly in Xalda population if breeders do not implement appropriate mating strategies. If we had taken into account this information, we could have applied a more accurate breeding policy delaying the increase of inbreeding levels.

The number of known generations and number of equivalent generations characterize the shallowness of the available genealogical information. Despite the average number of known generations reaching approximately two for the whole pedigree, the number of equivalent generations is roughly 1.0 , showing no practical differences between males and females.

The coefficients obtained by regression of the individual inbreeding coefficients on the number of known generations or on equivalent generations are, respectively, of 0.01114 and 0.02078 . However, these are not good estimations of the increase of the inbreeding in our population. We could not trace any animal more than seven generations back. The trend of inbreeding in a population should be estimated only when individuals have sufficient ancestral generations. In pedigrees as short as we have in Xalda sheep, in which individuals do not have sufficient ancestral generations, we could not obtain an accurate estimation of the trend of inbreeding (TE BRAAKE et al. 1994) and, therefore, we could not obtain an accurate estimation of $N_{\mathrm{e}}$. The average $F$ of the current Xalda population is 0.01762 . If we use this figure as the realized inbreeding with respect to the base population we would obtain a $N_{\mathrm{e}}$ of 28.4. However, any estimation of $N_{\mathrm{e}}$ in our population is affected by the influence of the low quality of the underlying pedigree information on the computation of the individual inbreeding coefficients.

The values of $F$ and AR that we found in our breed are relatively high if we take into account the fact that, roughly speaking, half of the individuals in our pedigree do not have known parents. The proportion of inbred animals is relatively high. Inbred rams in use constitute $10 \%$ of the total and their average $F$ is $12.5 \%$. These values are higher than those 
showed by DJeLlali et al. (1994) in the conservation programs of Solognote and Mérino Précoce breeds, who reported the existence of $10 \%$ of inbred active rams, although showing average inbreeding of $0.5 \%$. The combined information offered by both $F$ and AR parameters suggests that the pedigree is not structured in subpopulations. Populations bred under natural mating are usually genetically divided by herds. In these cases, we find high inbreeding values both at a herd and population level, but low values of AR. This means that inbreeding can be solved by the introduction of non-related males in herds (GutiérRez et al. 2003), which does not seem practical in the case of Xalda.

Our results could support the idea that inbreeding is not the best indicator of the risk of losing genetic diversity in a population. When a population is open to the introduction of new individuals with unknown pedigree, we could not adequately assess the actual level of inbreeding (and consequently the effective size) in a population level. In such a situation, an unobserved genetic drift may lead to losses of genetic diversity. In addition, it is difficult to solve the problems arising for high inbreeding coefficients when populations do not show genetic structure. Parameters such as AR can be used as an alternative or complement to $F$ to predict the long-term inbreeding of a population and to suggest modifications to management practice to conserve the genetic makeup of a population. AR takes into account the percentage of the complete pedigree originating from a founder in a population level. Of course, when the breeding goal is the conservation of genetic diversity, this information is useful for the management of a small population as it makes it possible to balance the contribution of a founder by itself or by means of its sons. Additionally, AR can be used in a herd or line level. Using AR, it is possible to determine the percentage of genetic contribution of a given line or strain of founders in the whole population, regardless of the actual number of initial founders lines or founder individuals per line. This can be used to balance the genetic contribution of the different strains, thus avoiding genetic losses arising from unsuitable management practices. Moreover, we can compute AR for each non-founder individual, to know the genetic representation of this individual on the population. We can use this information to indirectly characterize the herds as components of the whole population. We can add up the AR values of the individuals included in a herd as an indicator of the degree of inbreeding and coancestry within each herd. If we find relatively high mean AR values in a herd, we should recommend opening it up to new, under-represented animals.

Thus, we can apply the advantages of AR to describe our population in a more accurate way. In Table 6 we can see the genetic contributions of the nine distinct lines that breeders recognize as existing in Xalda sheep computed as the sum of the AR coefficients of founders assigned to them. Despite the individuals building these lines being only $48 \%$ of the equivalent number of founders of the breed, the genetic representation of the lines sum

Table 6. Genetic contribution of the nine recognized lines in the Xalda sheep breed to the total genetic variability of the population characterized as the number of founders included in these lines and the sum of the AR coefficients (in percentage) of these individuals

\begin{tabular}{|lrr|}
\hline Line & AR & $N$ \\
\hline Adrao & 2.6 & 13 \\
Antón & 3.9 & 4 \\
Arquil.lina & 1.1 & 6 \\
Brañaseca & 20.8 & 60 \\
Candanéu & 6.8 & 12 \\
Eilao & 4.6 & 16 \\
Eirrondo & 2.9 & 7 \\
Ixuxú & 11.8 & 26 \\
Oubal.lu & 9.8 & 29 \\
Total contribution & 64.2 & 173 \\
\hline
\end{tabular}


up more than two-thirds of the diversity of the breed. We can additionally observe that some lines are over-represented. The Brañaseca, Ixuxú and Oubal.lu lines sum up 47\% of the genetic variability of the breed.

\section{Implications}

Ideally, the conservation of genetic stock should begin with complete information on population size, distribution and structure. However, this is not the case in many endangered populations of domestic animals. In this sense, Xalda sheep can be considered as a representative example of the initiatives in conservation of animal genetic resources developed in Europe during the last decades of the 20th century. Major efforts have been made to recover individuals and assure pure breeding matings. However, the structure of populations and management practice can lead to abusive use of some reproductive individuals, thus inducing an undesirable loss of genetic diversity.

Traditional parameters based on inbreeding and effective size do not seem to be as effective as needed when we want to conserve the genetic makeup of a population that is not well established. When pedigree information is shallow, we underestimate the number of inbred individuals and the average inbreeding coefficient, but give relatively high inbreeding coefficients for inbred animals (Te BraAKe et al. 1994). SimON (1999) proposed the calculation of the maximum values of inbreeding in 50 years of conservation $\left(F_{\mathrm{g}}\right)$ to classify the endangerment of a population. $F_{\mathrm{g}}$ would be computed as $F_{\mathrm{g}}=1-(1-\Delta F)^{g} g$ being the number of generations in 50 years, assuming the average generation length as the generation interval. If we use our average generation length as $g$ and the regression coefficient of inbreeding on equivalent generations as $\Delta F, F_{\mathrm{g}}$ for our breed is 29.78. Thus, following Simon's classification (1999), the Xalda breed would be minimally endangered, which is not the overall impression that we can obtain starting from the analysis of our pedigree.

In a situation like that described in this study, no simple tool is useful to classify the situation of risk of a population. The use of new parameters such as average relatedness can be very interesting for monitoring small populations. Using AR, founder contribution can easily be equalized at a population level. AR provides information both for description and management purposes. In this sense, AR may be more useful than other parameters based on the estimation of the contribution of founders to the populations, such as those proposed by LACY (1989), Alderson (1991) or Boichard et al. (1997) which, strictly speaking, are only useful to describe populations. Moreover, the cost of computing $\mathrm{AR}$ is lower and is very easy to explain and understand for breeders. In addition, AR can be used values both at a herd and line level to characterize the level of risk of a population. This is especially interesting because of the knowledge of the structure of a population at herd level gives major information on the status of endangerment of a breed (Hall 1986, 1989).

As the breeding goal is the equalization of the genetic representation of founders, we can make some practical suggestions based on the use of AR to improve the management of genealogical information. The whole pedigree can be monitored after each birth season, computing the AR coefficient for each individual. This information can be used for mating purposes and to equalize the relative genetic representation of different lines and herds in relation to the population. The selection of the rams to initiate the breeding program aimed at avoiding losses of genetic diversity in our population must be carefully planned. The program should begin by using rams showing the lowest possible AR coefficients. The mothers of rams can be selected from the better conformed of the less genetically represented ewes. Breeders should ensure the use of at least one ram of each line in each generation. The putting into effect of the above recommendations can be easily implemented and are not especially demanding for breeders. 


\section{Acknowledgements}

This work was partially funded by a grant from INIA, no. RZ02-020, the Xalda sheep breeders association (ACOXA; http://www.acoxa.com/) and the Regional Government of the Principado de Asturias. The authors would like to thank the members of ACOXA, and especially Antón Alvarez Sevilla, for their kind support. We also appreciate comments and critical review of the manuscript by two anonymous referees.

\section{References}

Alderson, G.L.H., 1991: A system to maximize the maintenance of genetic variability in small populations. In: Alderson, L. (ed.), Genetic Conservation of Domestic Livestock, CAB International, Wallingford, pp. 18-29.

Alvarez Sevilla, J. A.; García Peláez, A.; Cortés Pérez, J., 1982: Descripción de la oveja de raza Asturiana. Biol. Cien. Nat. I.D.E.A. 30: 147-157.

Alvarez Sevilla, A., 2001: Les races autóctones del Principáu d’Asturies, pp. 11-18. Fundación Belenos, 33007 Uviéu/Oviedo (Principau d'Asturies).

Ballou, J. D.; LACY, R. C., 1995: Identifying genetically important individuals for management of genetic variation in pedigreed populations. In: Ballou, J. D.; Gilpin, M.; Foose, T. J. (eds), Population Management for Survival and Recovery, Columbia University Press, New York, pp. 76-111.

BARKER, J. S. F., 1957: The breed structure and genetic analysis of the pedigree cattle breeds in Australia. I. The Jersey. Aust. J. Agric. Res. 8: 561-586.

Boichard, D.; Maignel, L.; Verrier, E., 1997: The value of using probabilities of gene origin to measure genetic variability in a population. Genet. Sel. Evol. 29: 5-23.

Djellali, A.; Vu Tien Khang, J.; De Rocambeau, H.; Verrier, E., 1994: Bilan génétique des programmes de conservation de races ovines Solognote et Mérinos précoce. Genet. Sel. Evol. 26 (Suppl) 1: 255s-265s.

Dunner, S.; Checa, M. L.; Gutiérrez, J. P.; Martín, J. P.; Cañó, N. J., 1998: Genetic analysis and management in small populations: the Asturcon pony as an example. Genet. Sel. Evol. 30: 397405.

Gama, L. T.; Delgado, J. V., 2000: Assessing the risk status of a breed. In: Proceedings of the 5th World Conference on Conservation of Animal Genetic Resources. Brasilia (Brazil), 20-25 November 2000. CDD 591.15 Copyright EMBRAPA, Brasilia, Brasil.

Gutiérrez, J. P.; Altarriba, J.; Díaz, C.; Quintanilla, R.; Cañón, J.; Piedrafita, J., 2003. Genetic analysis of eight Spanish beef cattle breeds. Genet. Sel. Evol. 35.

Hall, S. J. C., 1986: Genetic conservation of rare British sheep: the Portland, Manx Loghtan and Hebridean breeds. J. Agric. Sci. 75: 13-39.

HALL, S. J. C., 1989: Conserving and development minority British breeds of sheep: the example of the Southdown. J. Agric. Sci. 112: 39-45.

LACY, R. C., 1989: Analysis of founder representation in pedigrees: founder equivalents and founder genome equivalents. Zoo. Biol. 8: 111-123.

LACY, R. C., 1995: Clarification of the genetic terms and their use in the management of captive populations. Zoo. Biol. 14: 565-578.

Meuwissen, T. I.; Luo, Z., 1992: Computing inbreeding coefficients in large populations. Genet. Sel. Evol. 24: 305-313.

Prod'homme, P.; Lauvergne, J. J., 1993: The Merino Rambouillet flock in the National Sheep Fold in France. Small Rumin. Res. 10: 303-315.

RoberTson, A., 1953: A numerical description of breed structure. J. Agric. Sci. 43: 334-336.

SIMON, D. L., 1999: European approaches to conservation of farm animal genetic resources. AGRI 25: 79-99.

Te Braake, M. F. H.; Groen, A. F.; Van Der Lught, A. W., 1994: Trends in inbreeding in Dutch Black and White dairy cattle. J. Anim. Breed. Genet. 111: 356-366.

Vassallo, J. M.; Díaz, C.; García-Medina, J. R., 1986: A note on the population structure of the Avileña breed of cattle in Spain. Livest. Prod. Sci. 15: 285-288.

WrIGHT, S., 1931: Evolution in mendelian populations. Genetics 16: 97-159.

Author's addresses: F. GoYACHE (correspondence and reprints; e-mail: fgoyache@serida.org), I. FERNÁndez, E. Gomez, I. Alvarez, J. Díez, L.J. Royo, SERIDA-CENSYRA-Somió, C/Camino de los Claveles 604, E-33203 Gijón (Asturias), Spain. J.P. Gutiérrez, Departamento de Producción Animal. Facultad de Veterinaria. Avda. Puerta de Hierro s/n, E-28040-Madrid, Spain. J. Díez, present address: Centro de Inteligencia Artificial, Universidad de Oviedo at Gijón, Campus de Viesques, E-33271 Gijón (Asturias), Spain. 
Copyright $\odot 2003$ EBSCO Publishing 
Copyright of Journal of Animal Breeding \& Genetics is the property of Wiley-Blackwell and its content may not be copied or emailed to multiple sites or posted to a listserv without the copyright holder's express written permission. However, users may print, download, or email articles for individual use. 